\title{
STOICISM AND THE IMPOSSIBILITY OF SOCIAL MORALITY
}

\author{
ANDREI SEREGIN \\ Institute of Philosophy RAS (Moscow) \\ avis12@yandex.ru
}

\begin{abstract}
Stoic ethical theory is famously "rigorist" in the sense that it regards all kinds of generally recognized non-moral goods and evils as "indifferents" that do not influence human happiness or misery. One of the problems with rigorism is that prima facie it seems to make impossible even a rudimentary social morality, for if non-moral evils, experienced by the victims of various inhumane actions, actually do them no harm and do not contribute to their being unhappy, then why should we regard the infliction of these evils as morally wrong? In this paper I examine the question of whether such a critique of Stoic rigorism (put forward, for example, by Claudia Card in her book "The Atrocity Paradigm") is justified. I argue that, on the one hand, one cannot find convincing counterarguments against it within Stoic tradition itself (e.g, the distinction between "preferred" and "rejected" indifferents, in my view, is of no avail for the Stoics in this case), but, on the other, the validity of this criticism depends on what we take to be the ultimate normative standard of moral evaluation. It is only valid under the assumption that some kind of "humanistic consequentialism" (as I call it here) is true. I also try to demonstrate that, if this kind of consequentialism is true, then similar criticism may be applied to many other ethical theories regardless of whether they endorse rigorism or not. (Personally, I believe "humanistic consequentialism" to be true, although I do not argue for this thesis here).
\end{abstract}

KEYWORDS: ancient ethics, good and evil, indifferents, normative ethics, social morality, Stoicism.

It is well known that according to one of the central tenets of Stoic ethics all kinds of generally recognized non-moral goods and evils (e.g., life and death, health and illness, pleasure and pain etc.) are actually something "indifferent" ( $\alpha \dot{\delta} \alpha \dot{\alpha} \varphi \circ \rho \alpha)$, i.e. no goods and no evils at all, and do not influence human happiness or unhappi- 
ness. ${ }^{1}$ The only existing good and evil which our happiness and unhappiness completely depend upon are exclusively moral in nature. ${ }^{2}$ For the sake of brevity I will further refer to this position as "(Stoic) rigorism". In my opinion, a fairly obvious, but not very often discussed problem with rigorism is that prima facie it makes simply impossible even a rudimentary social morality. For intuitively it may seem quite clear that those forms of moral evil that one might call paradigmatic $^{3}$ (e.g., murder, torture, rape, violence and, generally speaking, everything that usually is described as "atrocity") consist precisely in the infliction of nonmoral evils upon others. But if, for example, sufferings ${ }^{4}$ experienced by the victims of such actions do not constitute any evil, it becomes hard to understand why should we find any evil in the infliction of these sufferings, i.e. in those actions themselves. And lack of understanding in this respect is tantamount to the collapse of social morality. In this paper I want to examine the question of whether such a critique of Stoic rigorism is justified. In my opinion, the answer to this question must vary depending on what we believe to be the ultimate standard of moral evaluation. Personally, I do share those normative standards that make this kind of criticism quite legitimate. And I will also try to demonstrate that, if it is legitimate, then similar claims can be made about many other moral theories, which are of great significance in the history of European ethics, but do not necessarily endorse rigorist stance.

Perhaps the most straightforward formulation of this problem in contemporary philosophical literature may be found in Claudia Card's book "The Atrocity Paradigm", where she offered the following critique of Stoic rigorism:

"Even though Epictetus did not count suffering cruelty an evil, he did not want to deny that inflicting cruelty (being cruel) is evil, although it remains mysterious why. Cruelty is, apparently, a misuse of the will. The important things, he finds, are to resist becoming evil and to resist being defeated by the evil that others do... But if cruelty to

\footnotetext{
${ }^{1}$ E.g., SVF I, 185; 190 (= III, 70); 359; III, 33; 35; 129; 181; 39 Diog.; Sen. Ep. 94, 7-8; 120, 1-3; 123, 16; Epict. Diss. I, 24, 6-7; I, 28, 14-17. 22-23. 26-27; I, 30, 2-3; II, 9, 15; II, 19, 13; IV, 1, 133. M. Ant. II, 11 (4); V, 12; 15; 26; VI, 33; 41; VII, 31; VIII, 10; 28; IX, 1 (3); X, 30; XII, 23. Most abbreviations I use are those adopted in LSJ, OLD and PGL.

${ }^{2}$ E.g., SVF I, 362; 577; III, 16; 29-31; 35-38; 40; 51; 79; 139; 587; Sen. Ep. 31, 5; 71, 4-7. 19. 32; 76, 6-7. 16. 19. 21; 90, 34-35; 118, 10-11; M. Ant. II, 1; V, 34; VIII, 1; IX, 16; 42 (2); XI, 18 (3).

${ }^{3}$ I.e. both most radical and most widely recognized or agreed upon.

${ }^{4}$ To simplify matters, one can reduce all non-moral good and evil to pleasure and pain, respectively, as hedonists would do, although, of course, it is still possible to criticize rigorism proceeding from some non-hedonist (and, perhaps, pluralist) theory of non-moral values.
} 
others does them no harm, why is it wrong? To say that it harms the perpetrator ${ }^{5}$ begs the question. For it harms the perpetrator only if it is wrong... If it is impossible to harm others who place no special value on what eludes their control, stoics could not be harmed by anything others did to them, even though their bodies could be maimed and their lives terminated. For the stoic, to inflict or suffer a loss merely of "what one reasonably prefers" is not to inflict or suffer true harm. One is harmed only by having the wrong attitudes, and the attitudes we have, according to the stoics, are up to us $^{6} .$. If those who value what eludes their control are thereby responsible for their own misery when they suffer at the hands of others, ${ }^{7}$ stoic wrongdoers cannot truly harm others, let alone do them evil. If they harm anyone, it is only themselves (by holding the wrong values). For the stoic, all that evil can possibly consist in is wrongdoing itself. All evils are, apparently, self-inflicted... Stoicism... leaves little or no room for ethics in interpersonal relationships and social interaction... Would stealing wrong anyone, if no one should be so attached to worldly goods as to suffer greatly from their loss? Why regard even murder as a wrong, if the true self is invulnerable? If morality in particular, as distinct from ethics in general, is socially oriented, it appears that stoics should reject most of morality, or at least the importance most people attach to it today". ${ }^{8}$

I would not say that questions raised by Card are very often discussed by scholars who study Stoicism or ancient philosophy in general. ${ }^{9}$ This could be due to a number of factors, which partly obscure this problem and partly allow to treat it as a result of some basic and rather trivial failure to understand Stoic ethics. First of all, despite certain "Cynic" tendencies of its early period ${ }^{10}$ and also the notorious criticism of compassion as a morally bad emotion, "Stoicism on the whole produces an impression of a doctrine that entirely supports conventional social morality, insists on the necessity to fulfil one's duties towards relatives, fel-

\footnotetext{
${ }^{5}$ My guess is that here Card has in mind the Stoic idea that immoral actions harm the perpetrator by making her morally worse. See, e.g., SVF III, 289; 626; Epict. Diss. II, 10, 2428; IV, 1, 119-121; 5, 10; M. Ant. II, 16; IV, 26; VIII, 55; XII, 16.

${ }^{6}$ See, e.g., SVF II, 1118; III, 32; 215; Muson. Fr. 38 Lutz; Epict. Diss. I, 25, 1-4; 29, 4. 12. 47; II, 5, 4-5; 13, 10; III, 8, 2-3; 2O 1; IV, 1, 133-134; Ench. 31, 2; cp. SVF III, 224; 578; Sen. Ep. 41, 1; 8o, 3-4; M. Ant. V, 5; 10 (2); VII, 71; VIII, 29; 47; 55-56; IX, 31; 40; X, 13; 33 (2-3).

${ }^{7}$ I think that this may be the meaning behind SVF III, 289, 15-17 (pace Pohlenz 1939, 15). See also Epict. Ench. 3 o.

${ }^{8}$ Card 2002, 70-71 (the italics are in the text). Cf. on the whole pp. 65-72, and also the earlier version of these ideas in Card 1998, 245-253.

${ }^{9}$ Card herself did not belong to them (as is clear enough from Card 1998, 248), but she derived inspiration from some (in my opinion, less definitive and more cautious) ideas of Martha Nussbaum (Nussbaum 1995, 378-380). See also n. 62.

${ }^{10}$ SVF I, 584 ; II, 1072; III, 743-753.

${ }^{\text {"I }}$ SVF I, 434; III, 412-416; 450-453; 640-641.
} 
low citizens ${ }^{12}$ or even humankind in general, ${ }^{13}$ and, of course, unequivocally takes the side of such traditional social virtues as justice. ${ }^{14}$ This fact, however, may rather seem to emphasize the inconsistency inherent in Stoic doctrine: the question is exactly what reasons the Stoics have to endorse this position if they reject those very non-moral values which, as it prima facie seems, must be accepted in order that all these social duties and virtues could become conceivable.

Secondly, the Stoics themselves, as a rule, insisted on the directly opposite thesis: in their view, it is rather by admitting the existence of non-moral goods and evils that we undermine social morality. ${ }^{15}$ The problem they are concerned with in this case is quite different, though. Card's approach essentially implies that rigorism makes social morality logically impossible. The question "If cruelty to others does them no harm, why is it wrong?" presupposes ${ }^{16}$ that cruelty can only be (morally) wrong on the ground that it causes (non-moral) harm or evil to others. But this means that the very notion of moral evil already involves the notion of non-moral evil and cannot be explained or elucidated without it, so that by rejecting the latter we make the former impossible as well. The Stoics on their part rather mean that the recognition of non-moral goods and evils psychologicalby obstructs the realization of social virtues or even makes it impossible. The desire to obtain non-moral goods and to avoid non-moral evils is identified by them as the basic motive behind antisocial or "unjust" activities. Regardless of whether (or to which extent) these considerations are justified, ${ }^{17}$ they certainly cannot

\footnotetext{
${ }^{12}$ E.g., SVF III, 38; 333; 611; 616; 731; 757; 63 Ant.; Sen. Ep. 88, 7; 93, 4; 123, 12; Epict. I, 23; II, 7, 3; 10, 7-11; III, 2, 4; 10, 19; 24, 44-48; Hierocl. apud. Stob. III, 39, 34-36; IV, 24a, 14; 25, 53;

${ }^{13}$ SVF III, 340; 342; 492; Hierocl. apud. Stob. IV, 27, 23; cf. Anon. in Tht. 5, 24-32 DielsSchubart.

${ }^{14}$ E.g., SVF I, 200; 374-375; 558; III, 43; 255; 263-264; 280; 303; 320; 348; 689; Sen. Ep. 94, 11; 97, 15; 113, 31-32; Epict. Diss. I, 22, 2; III, 14, 13-14; 24, 52; 26, 32; IV, 1, 133; Cic. Fin. III, 25; 39; 66-67; 70-71; 73; Muson. 14, 32-36 Lutz; M. Ant. II, 5; III, 6 (1); 11 (3); 16 (2); IV, 18; 22; 25; V, 12; 34; VI, 30 (1); 47; VII, 28; 54; 66; VIII, 1; IX, 1; 31; X, 11; XI, 1 (3); XII, 1 (1); 3; 27; 29.

${ }^{15}$ E.g., SVF III, 21; 24; 157; 107 Diog.; Sen. Ep. 66, 16-17; 76, 22-24; 85, 16; 95, 37; 101, 15; Dial. (De vita beata) VII, 15, 4; Epict. Diss. I, 18, 13-14; 22, 14; II, 22, 9-11. 15-20. 28; III, 3, 5-10; 7, 11-17; IV, 5, 29-32; 7, 9-11; M. Ant. II, 10; VI, 16; 41; IX, 1; XI, 10; 18 (3); cf. Muson. 20, 50-64 Lutz.

${ }^{16}$ At least as interpreted by Card, since by "harm" she seems to understand exclusively non-moral evil or suffering (e.g., Card 2002, 14 and 16).

${ }^{17}$ They become especially pressing provided one accepts straightforward psychological egoism in the vein of Epictetus, who proceeds from the assumption that a human being cannot but eagerly seek what she believes to be good or beneficial for herself (Epict. Diss. I, 19, 11-15; 22, 14-16; 27, 12-13; 28, 6; II, 22, 15-20; 26, 2; III, 3, 2-10; 7, 14-15; 24, 83; IV, 1, 134-137; 5, 29-32). On the other hand, Chrysippus seems to admit that justice only
} 
outweigh the problem raised by Card. If it is true that by rejecting non-moral good and evil rigorism makes the very notions of moral good and evil logically impossible, then any statement to the effect that the recognition of non-moral good and evil psychologically hinders morally right activities makes no sense whatsoever: if moral good and evil are impossible, there can be no morally right activities anyway.

Finally, the third and, to my mind, far more weighty objection against Card's position may consist in the claim that it neglects important and rather obvious aspects of Stoic value theory. It is well known that with the exception of such radical rigorists as Aristo of Chios the majority of Stoics, while qualifying non-moral goods and evils as "indifferent" in relation to happiness or unhappiness, still

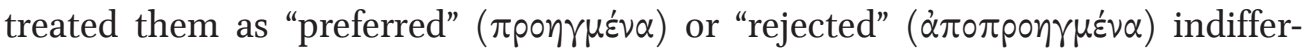
ents. ${ }^{18}$ The former, in their opinion, have a positive and the latter a negative value ( $\dot{\xi} \xi \dot{i} \alpha$ and $\dot{\alpha} \pi \alpha \xi \dot{\alpha} \alpha$, respectively), ${ }^{19}$ although not from eudaimonistic, but rather from what one might call naturalistic point of view. In other words, these values are ascribed to them on the ground that preferred things contribute to the preservation and full-fledged functioning of animal or human individuals, whereas rejected things hinder or block it. ${ }^{20}$ It is this distinction between what is preferred and what is rejected that seems to make it possible for the Stoics to retain the conception of social morality. It may be that in this respect the matter stands roughly as in the case of the egoistic concern for one's own non-moral well-being. At first glance, rigorism appears to make impossible this prudential aspect of human activities as well, for if there is no non-moral good or evil, then why should anyone try to avoid one's own desease, poverty, death and so on? Nevertheless, while introducing the distinction between preferred and rejected indifferents, the Stoics insist that in most cases, i.e. if one lays aside $x \alpha \theta \dot{\eta} \kappa o v \tau \alpha$ $\pi \varepsilon p \downarrow \sigma \tau \alpha \tau i x \alpha^{21}$ and, probably, what sometimes is called "Regulan behaviour", ${ }^{22}$ a

becomes impossible if pleasure is regarded as the highest good and not simply as one good among others (SVF III, 23).

${ }^{18}$ SVF I, 192-194; III, 62; 117; 122; 125; 127-129; 133-137; 139; 145; 181; 192. For Aristo's position, see SVF I, 351; 36o-362; 364-365; 367-368; 415; III, 19 o.

${ }^{19}$ SVF III, 118; 122; 124; 126-130; 133; 143.

${ }^{20}$ E.g., SVF III, 126; 145; 165; 180; 181; 47 Diog.; cf. I, 191; 232. In this respect they are regularly designated as things that are either "in accordance with nature" ( $\tau \dot{\alpha} \varkappa \alpha \tau \dot{\alpha} \varphi \dot{v} \sigma \nu)$ or "contrary to nature" ( $\tau \dot{\alpha} \pi \alpha \rho \dot{\alpha} \varphi v ́ \sigma$ v) (SVF I, 239; III, 124; 135; 140-143; 155; 188; 191; 195; 499; $759 ; 763 ; 766)$.

${ }^{21}$ I.e. those duties that are conditional on specific circumstances and at least fairly often imply that an agent should endure some hardships and, perhaps, even death. The 
Stoic sage will actually "select" ( $\lambda \alpha \mu \beta \dot{\alpha} v \varepsilon v v$; $\dot{\varepsilon} \chi \lambda \varepsilon \dot{\varepsilon} \gamma \varepsilon \sigma \theta \alpha$; sumere; seligere $)^{23}$ for herself nothing but preferred indifferents. ${ }^{24}$ And it seems possible that the same distinction could explain why, despite their rigorism, the Stoics consider it right to fulfil their social duties towards other people, i.e. at least not to cause them rejected things or maybe even to provide them with some preferred..$^{25}$

This objection would only make sense if Stoic notion of preferred and rejected indifferents really worked at least from prudential point of view, that is, if it really managed to explain in a rationally satisfying way, on the basis of which criteria a Stoic agent would select indifferents for herself provided that at the same time she remains a genuine and sincere rigorist. However, whether this notion succeeds in doing this, is far from being clear. In this rather short paper I cannot offer a thoroughly comprehensive discussion of this problem, ${ }^{26}$ and so I will limit my-

term is only used in SVF III, 496, but the general idea is present, e.g., in SVF III, 191; 757$759 ; 763 ; 766-768$.

${ }^{22}$ I borrow this expression from Barney 2003, 325. This kind of behaviour implies that it is necessary for an agent to give up something which is preferred or even to undergo something which is rejected for the sake of moral virtue, just as Roman politician Regulus did when he returned to Carthage to be tortured and executed in order to keep the promise he had given to Carthaginians (Cic. Off. I, 39; III, 99-115; Sen. Dial. (De prov.) I, 3 , 9-11; Ben. V, 3, 3; Dial (Tranq.) IX, 16, 4; Ep. 67, 7. 12; 71, 17; 98, 12). Scholars' opinions differ on whether "Regulan behaviour" can be consistently integrated into Stoic ethical framework. Traditionally, it was perceived as a quite authentic Stoic idea (see, e.g., Inwood 1985, 210-211 and Irwin 1998, 233), but Brennan 2005, 182-230, regards it rather as a distortion of Stoic teaching (Ibid., 182-183, 196-198, 210-211, 220), characteristic, e.g., of Cicero (Cic. Off. III, 13). Nevertheless, discussion of "Regulan behaviour" can be found in many Stoic sources (SVF III, 167; 181; 192; 577; 768; Sen. Ep. 14, 2; 66, 21; 67, 7; 76, 18-19. 26-27; cf. SVF III, 473, 32-37).

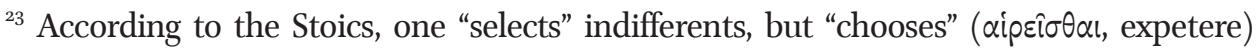
what is good. See esp. SVF III, 18; 123; 131-132 and, on the whole, I, 192; III, 118-119; 128; 142-143; 19o; 194-196; 256; 421; 427-428; 463; 44-46 Diog.; 48 Diog.; 57-59 Ant.; 21 Arch. This terminological distinction emphasizes that the good is to be "chosen" for its own sake, whereas preferred things are only "selected" because it is rational to do so (see also n. 31).

${ }^{24}$ This is manifestly implied in some of the Stoic definitions of the highest good ( $\tau \dot{\varepsilon} \lambda$ ○): SVF III, 12-15; 195; 44-46 Diog.; 57-59 Ant.; 21 Arch. Cf. also SVF I, 239; III, 138; 142; 148; 192; 498; 514; 572; 656; 688; 69o-691; 693; 698; 701.

${ }^{25}$ E.g., Irwin 1998, 234 and Brennan 2005, 214-215 seem to proceed from precisely this assumption. See also SVF III, 27.

${ }^{26}$ See general discussions, e.g., in Barney 2003, Brennan 2005 (esp. chapters 9, 12 and 13) and Klein 2015. A very good summary of traditional questions concerning Stoic conception of indifferents can be found in White 1990, 42-44. 
self to briefly describing what I believe to be its essence. It seems more or less clear that from the Stoic point of view:

1) all people seek happiness, which is their highest good and the ultimate goal of their actions ${ }^{27}$;

2) the only factor that can influence happiness or unhappiness is good and evil;

3) preferred and rejected indifferents by themselves, since they are neither good nor bad, are of no significance whatsoever for happiness and unhappiness (in accordance with 2);

4) the only good and evil are moral good and evil, i.e., first of all, virtues and vices (as states of the soul) and activities resulting from them;

5) happiness or unhappiness entirely depend on moral good or evil (in accordance with 2 and 4$)^{28}$;

6) actually, moral virtue itself as well as activity proceeding from it can only be thought of as some kind of capacity for, and practice of, rationally correct selection among indifferents ${ }^{29}$;

7) in most cases (i.e. with exception of $\varkappa \alpha \theta \dot{\eta} \kappa o v \tau \alpha ~ \pi \varepsilon p l \sigma \tau \alpha \tau i x \alpha$ and, perhaps, "Regulan behaviour") rationally correct selection consists precisely in an attempt to achieve preferred and to avoid rejected things for the agent herself ${ }^{30}$;

8) Stoic sages only make this selection for the sake of its rational correctness itself, because it constitutes their moral good (according to 6) and therefore their happiness (according to 5), and not in order to obtain something preferred or to escape something rejected as such (because of 1 and 3 ). ${ }^{31}$

The question is why, given all the rigorist premises $(1-5)$, it is precisely the selection of preferred indifferents that in most cases should be regarded as rationally correct? How are we to explain the exceptions from this rule? And finally, what is the ultimate standard or criterion by which one should decide whether selection is rationally correct or not in any possible situation?

Let us assume that this criterion is simply the inherent value of preferred and rejected indifferents themselves, which, as we saw, is naturalistic and not eudaimonistic in its content, that is to say, is based on the fact that the former contrib-

${ }^{27}$ E.g., SVF I, 554; II, 49, 27-28; III, 16-17; 280, 20-24; Cic. Fin. III, 11; V, 86; Sen. Dial. (De vita beata) VII, 1, 1; Epict. Diss. I, 4, 27-32; III, 23, 34; IV, 1, 46.

${ }^{28}$ For the sources of 2-5), see nn. 1-2.

${ }^{29}$ This logic stands behind the standard Stoic argument against Aristo, according to which, if we do not admit the distinction between preferred and rejected things, then virtue itself becomes impossible (SVF I, 364-365; III, 14; 27; 64; 114; 190; 194-195; 239; 766).

${ }^{30}$ See n. 24.

${ }^{31}$ E.g., SVF III, 11-12; 18-19; 44; 130; 193; 195-196; 363; 572; Sen. Ep. 85, 32. 
ute to the preservation and full-fledged development of individual natures, whereas the latter frustrate it. ${ }^{32}$ Of course, as any other conventional non-moral good or evil, even the preservation or destruction of human individuals is completely indifferent from the eudaimonistic point of view. ${ }^{33}$ But under the assumption made above the naturalistic value of indifferents somehow turns out to serve as the ultimate standard of eudaimonistic values. Indeed, it is on the ground of the inherent non-moral value of selected things that selection itself proves to be rationally correct, and it is because of its being rationally correct that it is practically identical to virtue and happiness. So that, if an agent wants to understand which specific selections would constitute her happiness and why, the ultimate thing she has to appeal to is the non-moral value of selected indifferents, which is at the same time declared to be of absolutely no importance for her happiness. To my mind, this basic contradiction suffices to conclude that such an approach is unsatisfactory. ${ }^{34}$

Besides, this interpretation makes it difficult to explain $\varkappa \alpha \theta \dot{\eta} \varkappa \circ v \tau \alpha \pi \varepsilon p\llcorner\sigma \tau \alpha \tau \iota x \dot{\alpha}$ and especially "Regulan behaviour". If rational correctness of selection is based on either positive or negative non-moral value of indifferents themselves, then it will always be right for an agent to maximize preferred things. ${ }^{35}$ Consequently, any choice in favour of something rejected (which is implied by the notion of

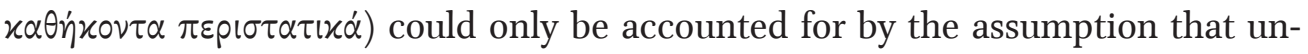
der these particular circumstances there is no other way to indirectly bring about

$3^{2}$ This view is adopted by Irwin (2007, 328; 331-332; cf. 1998, 229-234) who believes that, according to the Stoics, preferred indifferents deserve rational concern in their own right, and not simply because the successful exercise of human rationality with respect to them (as much as with respect to rejected things) constitutes virtue and happiness. I disagree, for I believe that the Stoics usually endorse 8). I do agree, though, that some Stoic texts may (at least, partly) corroborate Irwin's view (e.g., Sen. Ep. 92, 11). I just think that this makes their position inconsistent (see below) and in general undermines eudaimonism, i.e. 1) (for the criticism of Irwin's interpretation, see White 1990, 46-47 and Klein 2015, 249-252).

33 "Life and death" is a standard example of "indifferents" in Stoic texts (e.g., SVF III, 35; 7O; 114; 117; 120; 256, 21-23; Epict. Diss. I, 9, 13; 22, 12; 24, 6; II, 19, 13; M. Ant. II, 11).

${ }^{34}$ Cf. SVF III, 193.

${ }^{35}$ Logically, consequentialist talk of maximization can refer to at least five different types of outcomes, as Moore 2005, 10-11 has shown (with regard to pleasure and pain), but for the sake of brevity I will simply speak of "the maximization of preferred indifferents" to designate all of them. 
the maximization of preferred indifferents..$^{36}$ But as far as I can judge, Stoic sources and texts do not explicitly appeal to this kind of consequentialist reasoning. Moreover, it is incompatible with "Regulan behaviour". ${ }^{37}$ Any situation where an agent has to sacrifice something preferred or to endure something rejected in order to remain virtuous presupposes that it is in principle possible to choose between virtue and the maximization of preferred indifferents. But this is hardly conceivable if virtue itself can only be realized in the form of a rationally correct selection among indifferents, which in its turn consists in the persistent maximization of preferred things. For in this case any specific decision to prefer something rejected would be rationally incorrect and therefore vicious unless it indirectly maximizes preferred indifferents. And it is the essential characteristic of "Regulan behaviour" that rejected things are chosen exclusively for the sake of virtue and not in order to even indirectly maximize preferred indifferents for the agent. Actually, the agent may simply perish as a result of this choice. So that we have arrived at an obvious contradiction: "Regulan behaviour" that is supposed to be an example of perfect virtue must be rather seen as vicious. Perhaps, these problems could be solved if from the very start we took into account the social dimension of selection: for instance, an agent could prefer something rejected for herself in order to maximize preferred indifferents for others, ${ }^{38}$ and, if we had reasons to describe this specific type of behaviour as virtuous, ${ }^{39}$ this could account for "Regulan behaviour", although only in those cases where its social advantages are clear. However, the above-mentioned basic contradiction still obtains even in this case, so that on the whole this interpretation does not work.

The most attractive alternative to this approach is the idea that the ultimate standard of the rational correctness of selection and, consequently, of virtue itself is the conformity to universal nature, which within Stoic discourse can be simul-

\footnotetext{
${ }^{36}$ E.g., Forschner 1981, 200 explains $\varkappa \alpha \theta \eta \dot{\eta} \varkappa 0 v \tau \alpha \pi \varepsilon p \iota \tau \tau \alpha \tau \iota x \alpha$ as follows: “...unter zwingenden Umständen Naturwidriges verfolgt wird, um ein höheres naturgemäßes Gut zu erreichen”; Ibid., 219-220: “...man Naturwidriges wählt, um Naturgemäßes herbeizuführen”.

${ }^{37}$ See also Barney 2003, 324.

${ }^{38}$ See Barney 2003, 326-330 where this interpretation is traced back to Adam Smith. Cf. SVF III, 333 .

${ }^{39}$ Forschner 1981, 193 seems to simply take this for granted, but such an assumption may be rather problematic (see esp. Brennan 2005, 210-211, 215-217, 220-226). Besides, as is clear from the controversy between Diogenes of Babylon and Antipater of Tarsus (Cic. Off. III, 50-55 = SVF III, 49 Diog.; 61 Ant.; see also Off. III, 89-91; Anon. in Tht. 6, 17-29 Diels-Schubart), the Stoics were quite aware of the possibility of conflicts between selfregarding and other-regarding selection, although they did not necessarily believe that one should always prefer the non-moral interests of others to one's own.
} 
taneously presented as natural law, God's will, right reason or fate..$^{40}$ On this interpretation, the basic principle of rationally correct selection is that a Stoic sage would select both preferred indifferents (in most cases) and rejected ones (under specific circumstances) solely on the ground that this is what the will of universal nature most likely consists in. The fact that in some particular situation preferred things prevail or are easily obtainable should serve as a plausible indication that for the present universal nature wants the sage to continue living and functioning, as is appropriate for a being of her kind. But if preferred indifferents become hardly available and rejected ones prevail, this may mean that universal nature wants the agent to undergo hardships or even to cease to exist at all. ${ }^{41}$

This approach offers a rather good explanation of $x \alpha \theta \eta \dot{\eta} \kappa o v \tau \alpha \pi \varepsilon p \iota \tau \tau \alpha \tau i x \alpha$ and, perhaps, even of "Regulan behaviour", ${ }^{2}$ but, to my mind, in the last analysis does not work either. For conformity to the will of universal nature or God seems to be rationally correct not simply because this will is, as a matter of fact, insurmountable and therefore the most reasonable thing to do about it is to put up with it, ${ }^{43}$ but rather because it is rationally correct and virtuous in its own right. ${ }^{44}$ But what this

${ }^{40}$ It is this conformity that is implied in the Stoic definition of the highest good

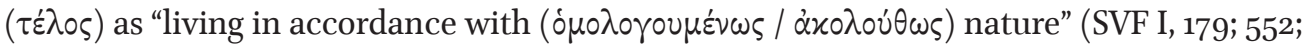
555; III, 4-9; 12; 149; 264, 31-36; 280, 20-24; 582). For this interpretation, see, e.g., Inwood 1985, 106-109, 156-164, 212-214; Striker 1996, 251; Cooper 2004, 224-225, 231-232.

${ }^{41}$ SVF I, 6o1; III, 191; 759; 763; Epict. Diss. II, 5, 24-25; 10, 4-6. This interpretation was further reinforced by the recent proposal made by Klein to rather understand the value of preferred and rejected indifferents as epistemic, i.e. precisely as their value for learning the will of universal nature in any given situation (Klein 2015, 258-277).

${ }^{42}$ At least, this interpretation does not imply that rationally correct and virtuous activity should necessarily lead to the overall maximization of preferred indifferents either for the agent herself or for others, since both these outcomes may well be against the will of universal nature.

${ }^{43}$ See, e.g., Sen. Ep. 61, 2-3; 107, 3-7; Epict. Diss. I, 27, 7-14; III, 24, 20-21.

${ }^{44}$ Natural law or God's will is at the same time ojp $\theta$ ò $\lambda$ 'óyos or recta ratio (SVF II, 1003; III, 4; 315-317; 319; 323; 325; 332; 337; 339; 36o; cf. II, 1119), and God or gods are in general good (SVF I, 529; II, 1005; 1116; III, 335; Cic. ND II, 33-36) and beneficent (SVF II, 528, 18-20; 1115; 1117; 1126; III, 668; 33-34 Ant.; Hierocl. apud Stob. II, 9, 7). Therefore, although the Stoics sometimes admit that the existence of rejected indifferents in the world is rather due to some insurmountable necessity or matter (SVF II, 1170; Epict I, 1, 7-12; II, 5, 27-28; Hierocl. apud Stob. II, 9, 7, 28-50 Wachsmuth-Hense), they are still able to insist that people should embrace whatever actually happens (e.g., Sen. Ep. 74, 12; Epict. Diss. I, 1, 27; II, 14, $7-8 ; 17$, 21-22; M. Ant. V, 8; VI, 39; VII, 54; 57) not because it is inescapable, but because, objectively speaking, this is the most preferable state of affairs (e.g., SVF II, 1181-1182; Sen. 
last statement could possibly mean? If human virtue is practically reduced to rationally correct selection among indifferents, then God's virtue must consist in analogous selection as well. ${ }^{45}$ God, naturally, shares the right conception of values, i.e. Stoic rigorism, but at the same time arranges the world by selecting in some specific way both preferred and rejected things that others have to experience. But in which sense can this selection be regarded as rationally correct? ${ }^{46}$ In the case of human activities the last standard of rational correctness was conformity to the will of God, but there seems to be no point in appealing to this criterion when it comes to God himself. To say that the will of God is rationally correct because it conforms to itself would be either an uninformative tautology or a pseudo-explanation, which essentially tries to present the actual state of affairs in the world as its own ultimate justification..$^{47}$ So that in the upshot we seem to be left without any intelligible standard of rationally correct selection carried out by human beings, for basically this standard boils down to the accordance with the similar selection performed by God, but why this last selection is rationally correct as well, the Stoics simply fail to clarify (although they seem to assume that it is).

If the preceding analysis is right, then, after all, the distinction between preferred and rejected things does not make it possible to explain in a rationally satisfying way, on the basis of which criteria a sincere advocate of Stoic rigorism could carry out both self-regarding and other-regarding selection among indiffer-

Ep. 96, 1-2; Epict. I, 12, 16-17; II, 7, 11-14; IV, 1, 99-102; VII, 19-20; M. Ant. II, 11; XII, 5; see also Striker 1996, 228-229; Cooper 2004, 235).

${ }^{45}$ Especially taking into account the typically Stoic idea that divine virtue, "right reason" or happiness do not essentially differ from human ones (SVF III, 54; 149; 245-252; $\left.339 ; 5^{26}\right)$.

${ }^{46}$ For specific factors God, according to the Stoics, takes into account in so doing (such as beauty, perfection and stability) see Wynne 2012. Cf. also Frede 1999, 75-77 and Cic. ND II, 58. But all these factors are, of course, certain types of indifferents, whereas the crucial question is by what standards the selection aimed at them is to be regarded as rationally correct and virtuous.

${ }^{47}$ From this point of view Stoicism starts to look like a version of divine command theory. Nor do I believe that this problem can be solved by interpreting God's rationality as some kind of perfect order and consistency of his thoughts (see Cooper 2004, 223-225, 235,242 ). It is not clear by what standards the goodness of this order itself should be assessed (e.g., what does it mean to call it "perfect", "best" etc.?), or how it could help us to determine whether the selection among indifferents carried out by God is rationally correct. Unless, of course, the supposed explanation amounts to saying that, since in some vague sense God is absolutely good and rational, and this should be taken for granted, everything he does is absolutely right. But then it would be simpler to say that we should accept it as a matter of faith. 
ents.$^{48}$ In this sense Card's critique of rigorism remains quite relevant. ${ }^{49}$ However, it is interesting to notice that we can find in Stoic tradition itself a fairly explicit anticipation of the questions raised by Card, and, what is even more interesting, the most original Stoic response to such problems does not appeal at all to the notions of preferred and rejected indifferents. What I have in mind here is the argument that Seneca sometimes resorts to in order to answer two following questions: first, if a sage on whom somebody inflicts non-moral evils actually suffers no evil and therefore no injustice either (injuriam non accepit), then in which sense one could still say that her offender really committed an injustice (injuriam fecit) and deserves moral blame $?^{50}$ Second, if non-moral goods one agent provides for another are actually no goods at all, then why should one think that the former agent has performed some beneficent act and the latter should be grateful to her? ${ }^{51}$ These questions essentially show how rigorism undermines the very possibility of such notions as justice and injustice, benefit and gratitide an so forth (at least in their conventional sense).$^{52}$ Seneca's reply basically comes down to saying

${ }^{48}$ There is also an interpretation which treats preferred and rejected indifferents as having different instrumental value for virtuous activity (Lesses 1989), but I agree with Klein's objections against it (Klein 2015, 242-245).

${ }^{49}$ Card 2002, 70: But why is the way one uses outward things not indifferent, if outward things themselves are? What defines how one uses a thing as a correct or incorrect use of the will? Stoics need to distinguish right from wrong uses of the will without appealing to the value of what exceeds our control. Yet I find in their writings no illuminating answer to the question of how to make that distinction.

${ }^{50}$ Sen. Dial. (De const. sap.) II, 7, 2-6; cf. Ben. II, 35, 2; VII, 7, 3-4. The idea that an agent who mistreats a sage is guilty of injustice, even though the sage does not suffer any injustice at all, is stated also in SVF III, 578-579, but, to my knowledge, only Seneca finds necessary to somehow justify it, although SVF I, 580 (= Sen. Ben. V, 14, 1) shows that the arguments of this kind were discussed already by Cleanthes.

${ }^{51}$ Ben. V, 13, 2-4.

${ }^{52}$ Cf. essentially similar peripatetic critique of Stoic rigorism in Anon. in Eth. Nic., p. 248, 1-36 Heylbut, according to which the notion of justice necessarily implies that people inflict good or evil on each other within all sorts of distributive or retributive social practices, and since, on the one hand, they cannot use moral good and evil for this purpose, and, on the other, rigorism denies that there is any non-moral good or evil, justice itself becomes completely "pointless" (ä $\chi p \eta \sigma \tau o v)$ under rigorist assumptions. Another and, apparently, more common antirigorist argument ran like this: since good ( $\dot{\alpha} \gamma \alpha \theta \dot{v} v)$

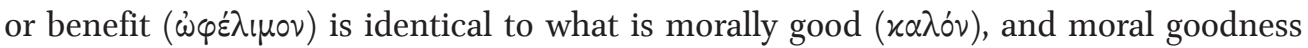
only depends on the agent's will (see n. 6), gods are completely unable to benefit people in any way (SVF II, 1118, 22-25; III, 32; 215; Plut. Comm. not. 1075ef; although the Stoics often insist that gods are beneficent, see n. 44). 
that in order to do something morally good or evil in relation to others it is enough just to intend to cause them some good or evil, respectively. But most people do not share rigorist position and, consequently, when causing preferred and rejected indifferents to others, they intend to cause them precisely good and evil. Therefore, we are thoroughly entitled to consider their actions as morally right or wrong. ${ }^{53}$ This view, which I would designate as subjectivist intentionalism, seems to me very questionable in itself, since it makes the very existence of genuine moral good and evil dependent on someone's erroneous ideas about nonmoral values. However, even greater problem for the Stoics is that this answer only proves Card's point. Indeed, by the same logic any agent who sincerely accepts Stoic rigorism can inflict on others any sufferings whatsoever without committing moral evil, for she believes, and quite rightly so, that thereby she does not cause them any evil, and, consequently, she cannot even intend to cause it. ${ }^{54}$ On the other hand, when such an agent provides others with preferred things or saves them from rejected ones, this behaviour cannot be described as morally good, because in her own view, which again is quite correct, she does them no good and, accordingly, cannot have such an intention. All this just once again demonstrates that rigorism is incompatible with conventional social morality.

So far I have been trying to show that within Stoic tradition itself one cannot find convincing counterarguments against Card's criticism of rigorist position. Nevertheless, in my opinion, it is still possible to raise a more general and conceptually more interesting objection_against her claims. In order to illustrate it by a specific example, which has to do with Stoicism, let us go back to the second interpretation of preferred and rejected indifferents discussed above and assume

${ }^{53}$ I think that this argument can be reconstructed on the basis of such texts as Sen. Dial. (De const. sap.) II, 7, 4-6; Ben. I, 6, 1-3; II, 35, 2; V, 13, 4- 14, 4; VII, 7, 3-4; Dial. (De ira I) III, 3, 1-2; (De vita beata) VII, 26, 5-7, but I cannot discuss here all the details of Seneca's argumentation.

${ }^{54}$ It seems reasonable to admit that a sincere supporter of rigorism would not inflict sufferings on others for egoistic reasons, i.e. in order to obtain non-moral goods or to avoid non-moral evils for herself. But she still could do it out of neglect, because she simply would not care about the possible non-moral consequences of her actions for others, or out of indifference, e.g. by not providing them with any help at all. To my mind, there is something strangely inconsistent, for example, in Marcus Aurelius' advice

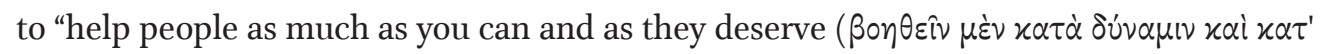

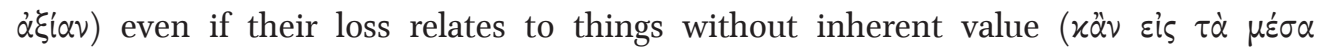
$\varepsilon \lambda \alpha \tau \tau \hat{\omega} \nu \tau \alpha \mathrm{l})$ ", but still "not [to] form the impression that this constitutes harm ( $\mu \dot{\eta} \mu \varepsilon \dot{\varepsilon} \tau 0 \mathrm{l}$

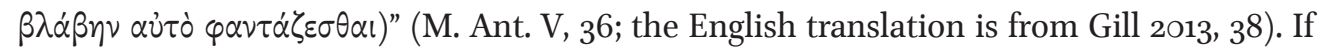
this does not constitute harm to them, then why believe that saving them from this "nonharm" constitutes "help"? 
that we somehow managed to explain in which sense the selection of indifferents by God's will is rationally correct. Apparently, in this case we would have at our disposal a rather abstract ${ }^{55}$ but consistent standard of rationality, which could be applied both to the selection of preferred things in most cases and to the favouring of rejected ones under very special circumstances. However, it is rather easy to see that on this interpretation seemingly "prudential" behaviour by a sage actually would not be anything of the sort: even if in most cases she would select for herself preferred indifferents, she would do it not for the sake of physical selfpreservation and not even for the sake of preserving her own rational nature, ${ }^{56}$ but on the sole ground that such is, in her view, the will of God or universal nature ${ }^{57}$ In fact, according to this construal, it is this motivation that makes her behaviour genuinely virtuous, transforming the act of selection from simple "duty"

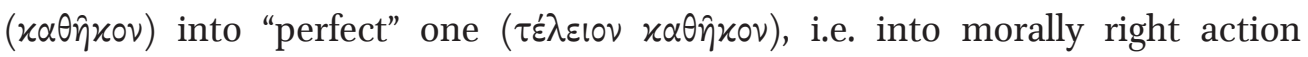
$(\kappa \alpha \tau o ́ p \theta \omega \mu \alpha) . .^{8}$ But any agent who performs the same action not for this reason, but, for example, because she mistakes preferred things for goods and rejected things for evils, still remains foolish and vicious. It is clear that by analogy similar reasoning should be applied to other-regarding selection as well: even if in most cases the sage considers it right to help others to get rid of rejected indifferents or to enjoy preferred ones, she behaves this way not because she really believes these consequences of her actions to be important (i.e. that others survive or, generally speaking, feel good and not bad), ${ }^{59}$ but only on the ground that such is at the moment the presumable will of universal nature. And it is only because of this that her actions are truly virtuous. But any agent who really cares how other people feel as a result of her activities, because she regards pleasure, pain and

${ }^{55}$ If we apply this criterion to specific situations, there will arise many hardly answerable questions similar to those raised by Brennan 2005, 312: "If my bread falls on the floor, may I pick it up, or should I take it that Zeus is sending me a message? If we're out of bread, should I run to the shop, or should I decide that fate has interceded to show me it wasn't meant to be? Or if I don't pick up the bread, or don't run to the shop, am I just failing to exercise the proper diligence in selection?" But this only shows that the normative standard in question does not offer clear decision procedures applicable in particular cases, and this problem is characteristic of many general normative theories.

${ }^{56}$ See Sen. Ep. 121, 14 (= SVF III, 184).

${ }^{57}$ Nevertheless, from the eudaimonistic point of view her behaviour can still be called "prudential" in the sense that this would be the only way for her to be virtuous and therefore happy.

${ }^{5}$ See., e.g., Inwood 1985, 212-214; Striker 1996, 235 and 252; Frede 1999, 82. For terminology, see SVF III, 494; 499-500.

${ }^{59}$ See M. Ant. V, 36 in n. 54, Epict. Ench. 16 and also Brennan 2005, 155-156. 
other indifferents as genuine goods and evils affecting their happiness and misery, precisely for this reason should be considered foolish and vicious.

Does it make sense to say that by adopting such a view Stoicism provides for the possibility of social morality? To my mind, at this point it becomes clear that the answer to this question depends on how we construe the notion of social morality itself. On the one hand, if the Stoics really can offer justification for some normative theory that in most cases would require a person not to cause others rejected indifferents or even help them to obtain preferred ones, then they seem to more or less warrant those results that are usually expected from conventional social morality. In this sense why not admit that Stoicism makes it perfectly possible $?^{60}$ From this point of view it may appear that the chief weakness of Card's claims against Stoicism lies in her not being quite aware of how narrow the normative premisses of her criticism really are. As I noticed earlier, the question "If cruelty to others does them no harm, why is it wrong?" presupposes that cruelty can only be (morally) wrong on the ground that it causes (non-moral) harm or evil to others. However, this could only be true if we have already agreed that it is the conduciveness of an activity to non-moral goods and evils for others (or, maybe, for everyone concerned including the agent herself) that is the ultimate standard of moral evaluation. In other words, we should have already accepted some version of altruistic or universalist consequentialism based on a certain theory of strictly non-moral values (hedonism, for instance) ${ }^{61}$ But it is clear that this specific type of normative theories, which for the sake of convenience I will call here "humanistic", even from the historical point of view emerged rather late, in the $17^{\text {th }}$ century at the earliest, ${ }^{62}$ and there exist many alternative normative

${ }^{60}$ I want to stress here once more that, in my opinion, the Stoics actually failed to provide a convincing justification for such a theory.

${ }^{61}$ By speaking here of "strictly non-moral values" I want to emphasize that we have to exclude any kind of consequentialist or broadly teleological theory that takes into account morally significant consequences and outcomes of human agency (e.g., "ideal utilitarianism", "outcomism" an so on).

${ }^{62}$ At least in Europe. In China Mozi seems to have endorsed similar view already in the

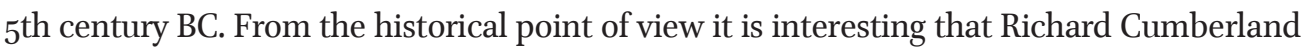
who is sometimes regarded as the founder of utilitarianism in European tradition (see, e.g., Schneewind 1998, 101) put forward an argument against Stoic rigorism, which basically anticipates that by Card: "Upon this head, the Stoicks are to be reprehended, who affirm'd, "nothing to be Good, but Virtue; nothing Evil, but Vice." For, whilst they endeavour to establish the transcendent Goodness of Virtue, and the egregious Evil of Vice, they, incautiously, intirely take away the only reason, why Virtue is Good, and Vice, Evil. For Virtue is therefore Good, (and in truth it is the greatest Good,) because it determines Human Actions to such effects, as are principal parts of the Publick Natural Good; and, consequently, tends to im- 
theories that propose to assess any activity, including the cruel one, from the standpoint of substantively different standards. For such theories there must be nothing strange in considering cruelty morally wrong, for example, on the ground that it is contrary to God's will or to the logical possibility of universalizing the maxim of action or to a certain version of social contract or to the agent's own good (if correctly understood) or to some immediate intuition tout court and so forth. Some supporters of these theories could also endorse rigorism, as many Platonists ${ }^{63}$ and Christians ${ }^{64}$ actually did, but, strictly speaking, this is not very important. For logically it is quite possible, on the one hand, to admit the existence of non-moral good and evil and, on the other, to believe that the moral assessment of an action should be based not on its conduciveness to non-moral goods and evils but on appeal to some other normative standard. ${ }^{65}$ Actually, this

prove in all Men the Natural perfections, both of Mind and Body, and to promote, as much as possible, the Honour of God, by imitating the Divine Beneficence. Further, seeing one part of Universal Justice (which is Virtue itself conspicuous among Men) consists in Innocence, that is, in restraining Murder, Theft,\&c. it is manifest, "That they can give no reason of the Law prohibiting such Injuries, unless they acknowledge, that such actions, as the robbing an Innocent person of his Life or Goods, (by which Life is preserv'd,) are Evil, or hurtful to one or more, antecedently to all Laws, and, consequently, without respect to Virtue, which consists in paying obedience to Law" (De legibus naturae V, 5; Parkin 2005, 508; for Latin text, see Cumberland 1720, 196-197). Cf. Striker 1996, 278 who makes essentially the same point: "The Stoics were no doubt right in saying that we evaluate others and ourselves as good or bad people according to moral standards and regardless of success or bodily attractions (Sen. Ep. 76.11-12), but this is not because moral virtue is the only true good, but presumably because virtuous conduct contributes or tends to contribute to the well-being of all members of society, and we evaluate people as good or bad qua members of society. The moral value of a person is indeed not a matter of her success, beauty, or wealth, but it does not follow that the value of virtue in general has nothing to do with the material welfare of human beings in general. Hence the contentment of the Stoic sage who is elated by her grandiose display of virtue in spite of her failure to achieve what she set out to do seems out of place, for in congratulating herself she shows contempt for the very things that made, not indeed this particular action, but this way of acting, good and admirable in the first place".

${ }^{63}$ E.g., Alcin. Intr. 27, 4-5; Attic. Fr. 2; 43 Des Places; Plot. I, 4, 4-8. 12-15; III, 2, 5, 6-7; III, 2, 6, 1-3 Henry-Schwyzer; Sallust. 9, 8; 21. Some passages in Plato's dialogues could be used to support this view, e.g. Ap. 3ocd; 41cd; Smp. 216e; Euthd. 281de; 292b; R. 613a; Grg. $527 \mathrm{~cd}$.

${ }^{64}$ E.g., Or. Cels. IV, 66, 10-13; VI, 54, 4-6; 55, 1-3 Borret; Gr. Thaum. pan. Or. 75-76; Bas. hom. 9 (PG 31, 333; 337-341); hex. 2, 5, 14-26 Giet; Gr. Naz. ep. 32, 5-7 Gallay; Chrys. stat. V, 2 (PG 49, 7O); Aen. dial. 19, 11 - 20, 19 Colonna; Jo. Cass. Conf. VI, 3-4.

${ }^{6}$ As Card herself seems to realize in respect to Kant (Card 2002, 73-74 and 82). 
last assumption seems to be simply necessary in order that normative theories alternative to "humanistic" consequentialism could exist at all. Rigorism just makes this as clear as possible, for if non-moral evil does not exist, cruelty definitely cannot be morally wrong because of the non-moral evils it produces. But in principle it can be morally wrong for many other reasons even if we agree that non-moral evil exists. In this sense the thesis that rigorism makes social morality impossible seems blatantly false if we are ready to admit that such a morality can possibly be based on "non-humanistic" normative foundations.

On the other hand, the basic idea behind Card's position may be precisely that we should not admit this. The gist of her antirigorist claims in that case would be that rigorism undermines not any theoretically possible morality whatsoever but rather the true one, for it is fundamentally incapable of understanding what is really so morally problematic about cruelty and atrocity. ${ }^{66}$ For instance, according to the above-mentioned interpretation of Stoic ethics, a Stoic sage can see something morally wrong with the crimes committed by the likes of, say, Gilles de Rais or Pol Pot for the sole reason that such actions presumably run counter to the will of universal nature which in a rationally justified way wants their victims to continue for the time being their basically indifferent existence, but by no means because such agents cause others horrendous sufferings. Intuitively, many of us would be inclined to agree that it is the last explanation that is obviously correct, whereas Stoic account of why these atrocities are examples of extreme moral evil is glaringly inadequate. Hence, the chief problem with rigorism is not that it makes the Stoics emotionally callous and insensitive to the sufferings of others, although this may be true, but rather that it radically distorts the very essence of moral good and evil and therefore of morality itself. ${ }^{67}$ However, such an intuition

${ }^{66}$ Card 2002, 71: "Stoics should have difficulty... regarding as an atrocity any deprivation of goods needed for survival and any infliction of bodily harm, regardless of how massive or even fatal”.

${ }^{67}$ Striker 1996, 276: "It is no comfort... to think that this virtuous person will risk her life to save a drowning child, but that she will not be sad or disappointed if she fails, being content with the reassuring knowledge that what she did, and also what happened, was in accordance with nature. What has gone wrong here is not, I think, the suggestion that we could be without emotion, but that we should try to be. And the reason for this lies not in the Stoics' theory of emotion, but in their theory of what is good or bad..."; cf. also Nussbaum 1995, 379: “...for Socrates, for the Stoics, for Spinoza, for Kant, it seems difficult to motivate consistently, given the alleged moral irrelevance of external goods, the self-sufficiency of the virtuous will. Repudiating pity, as they all do, leaves very few motives for the acts usually prompted by pity; and if they are performed out of very different motives, say, on account of pious obedience to Zeus's will, it is not clear that their moral character is the same". 
basically presupposes that we already share certain normative standards of "humanistic" type. It is for that very reason that similar criticism should be applied to all "non-humanistic" normative theories in general. For in this respect how do Card's antirigorist claims differ from H.L.A. Hart's caustic remarks about divine command theory ${ }^{68}$ or from similar statements by Schopenhauer about the whole range of classical moral doctrines including perfectionism, Kantian ethics and religiously motivated version of ethical egoism $^{69}$ ? On this interpretation, Card's criticism may be summed up as follows: a) rigorism makes logically impossible "humanistic" social morality, and since b) it is this kind of social morality that is the only true one, c) one can plausibly say that rigorism actually makes logically impossible social morality as such. But then it is made impossible by any "nonhumanistic" normative theory of moral value. Obviously, as a philosophical thesis, b) remains controversial, although hardly more so than similar pretensions on the part of alternative normative theories (including the presumably Stoic idea that morally right action can only take place when it is done out of desire to conform to the will of universal nature). However, for those who are unable to reject the above-mentioned "humanistic" intuition about why cruelty and atrocity constitute moral evil b) seems to be the only option left. In the last analysis, it is simply because personally I do share this basic intuition, that I believe Card to be right in her criticism of rigorist stance. In my opinion, it is essential to understand that what we have to deal with in discussing this problem is the irreconcilable

${ }^{68}$ Hart 1986, 52 (quoted in Coyle 2014, 74): "The moral monster who thinks there is nothing morally wrong in torturing a child except that God has forbidden it, has a parallel in the moralist who will not treat the fact that the child will suffer agony as in itself a moral reason enough".

${ }^{69}$ Janaway 2009, 221: "If we are informed of a very cruel deed, as is, e.g., the one that the newspapers are reporting just now about a mother who murdered her five-year-old boy by pouring boiling oil down his throat and her younger child by burying it alive; or the one that is just reported from Algiers, that after a chance dispute and fight between a Spaniard and an Algerian, the latter, being the stronger, tore the other man's whole lower jaw bone clean off and carried it away as a trophy, abandoning him still alive - then we are seized with horror and cry out: 'How is it possible to do such a thing?' - What is the sense of this question? Is it perhaps: How is it possible to fear so little the punishments of the future life? - Hardly. - Or: How is it possible to act on a maxim that is so highly unsuited to becoming a universal law for all rational beings? - Certainly not. - Or: How is it possible to be so negligent of one's own perfection and that of others? - Equally not. The sense of that question is quite certainly simply this: How is it possible to be so much without compassion? - Thus it is the greatest lack of compassion that impresses upon a deed the most profound moral reprehensibility and hatefulness. Consequently compassion is the real moral incentive". 
clash of rival normative standards, and the most important lesson one can derive from Card's reflections on Stoicism is that between "humanistic" and "nonhumanistic" conceptions of morality (in the sense I attach to these terms here) there can be no common ground whatsoever.

\section{ABbreViations}

LSJ - Liddell, H.G., Scott, R., H.S. Jones et al. A Greek-English Lexicon. With A Revised Supplement. Oxford: Clarendon Press. 1996.

OLD - Oxford Latin Dictionary. Oxford: Clarendon Press, 1968.

PGL - Lampe G.W.H. A Patristic Greek Lexicon. Oxford: Clarendon Press, 1961.

SVF - von Arnim, H. (ed.) Stoicorum veterum fragmenta. Vol. I-IV. Stuttgart: Teubner, 1964.

\section{REFERENCES}

Barney, R. (2003) “A Puzzle in Stoic Ethics," Oxford Studies in Ancient Philosophy 24, 303340.

Brennan, T. (2005) The Stoic Life. Emotions, Duty, and Fate. Oxford: Clarendon Press.

Card, C. (1998) "Stoicism, Evil and the Possibility of Morality," Metaphilosophy 29.4, 245253.

Card, C. (2002) The Atrocity Paradigm. A Theory of Evil. New York: Oxford University Press.

Cooper, J.M. (2004) "Stoic Autonomy," in J.M. Cooper, Knowledge, Nature, and the Good. Essays on Ancient Philosophy. Princeton \& Oxford: Princeton University Press, 204246.

Coyle, S. (2014) Modern Jurisprudence. A Philosophical Guide. Oxford \& Portland, Oregon: Hart Publishing.

Cumberland, R. (1720) De legibus naturae disquisitio philosophica. Dublini: Typis Jacobi Carson.

Forschner, M. (1981) Die stoische Ethik: über den Zusammenhang von Natur-, Sprach- und Moralphilosophie im altstoischen System. Stuttgart: Klett-Cotta.

Frede, M. (1999) "On the Stoic Conception of the Good," in K. Ieradiakonou (ed.), Topics in Stoic Philosophy. Oxford: Clarendon Press, 71-94.

Gill, C., tr. (2013) Marcus Aurelius. Meditations. Books 1-6. Oxford: Oxford University Press.

Hart, H.L.A. (1986) “Who Can Tell Right from Wrong?" New York Review of Books 33.12 (17 July 1986).

Inwood, B. (1985) Ethics and Human Action in Early Stoicism. Oxford: Clarendon Press.

Irwin, T. (1998) "Stoic Inhumanity," in J. Sihvola, E. Troels-Pedersen (ed.), The Emotions in Hellenistic Philosophy. Dordrecht: Springer-Science+Business Media, 219-242.

Irwin, T. (2007) The Development of Ethics. Vol. I: From Socrates to the Reformation. New York: Oxford University Press. 
Janaway C., tr. (2009) Arthur Schopenhauer. The Two Fundamental Problems of Ethics. Cambridge: Cambridge University Press.

Klein, J. (2015) "Making Sense of Stoic Indifferents," Oxford Studies in Ancient Philosophy 49, 227-282.

Lesses, G. (1989) "Virtue and the Goods of Fortune in Stoic Moral Theory," Oxford Studies in Ancient Philosophy 7, 95-127.

Moore, G.E. (2005) Ethics. New York: Oxford University Press.

Nussbaum, M.C. (1995) “Emotions and Women's Capabilities," in M.C. Nussbaum, J. Glover (ed.), Women, Culture and Development. Oxford: Clarendon Press, 36o-395.

Parkin, J., ed. (2005) Richard Cumberland. A treatise of the laws of nature. Translated, with introduction and appendix by John Maxwell (1727). Indianapolis: Liberty Fund, Inc.

Pohlenz, M. (1939) "Plutarchs Schriften Gegen die Stoiker," Hermes 74.1, 1-33.

Schneewind, J.B. (1998) The Invention of Autonomy: A History of Modern Moral Philosophy. Cambridge: Cambridge University Press.

Striker, G. (1996) "Following nature: A study in Stoic ethics," in G. Striker, Essays on Hellenistic Epistemology and Ethics. Cambridge University Press, 221-28o.

White, N.P. (1990) "Stoic values," The Monist 73.1, 42-58.

Wynne, J.P.F. (2012) "God's indifferents: Why Cicero's Stoic Jupiter made the world," Apeiron 45.4, 354-383. 